\title{
Damage and Fatigue Life Evaluation for Laser Cladding Remanufactured Wheel
}

\author{
Liang Hua $\mathbb{D}^{1,2}$ and Run-dong Zhou $\mathbb{D}^{1,2}$ \\ ${ }^{1}$ College of Locomotive Vehicle, Nanjing Institute of Railway Technology, Nanjing 210031, China \\ ${ }^{2}$ Collaborative Innovation Center on High-Speed Rail Safety of Ministry of Education, Nanjing 210031, China \\ Correspondence should be addressed to Liang Hua; hua672@163.com
}

Received 23 July 2021; Revised 26 January 2022; Accepted 1 February 2022; Published 3 March 2022

Academic Editor: Fernando Lusqui os

Copyright (C) 2022 Liang Hua and Run-dong Zhou. This is an open access article distributed under the Creative Commons Attribution License, which permits unrestricted use, distribution, and reproduction in any medium, provided the original work is properly cited.

\begin{abstract}
Owing to high speeds and heavy loads, the wheels of trains and locomotives undergo gradual but significant damage. Conventionally, these damaged wheels are repaired using the rotatory repair method; however, this approach results in large amounts of material waste. To address this issue, in this study, laser cladding remanufacturing technology was employed to repair a damaged wheel. The contact stress and creep characteristics of the cladded wheel were determined using Simpack, a dynamic simulation software program. The existing damage function model, which is based on the wear number, was modified, and this modified model was used to perform damage assessments for the remanufactured wheel. Furthermore, a life evaluation model for wheels remanufactured using this laser cladding technology was established. The service life of the cladded wheel calculated using this model was in good agreement with the design life of the wheel.
\end{abstract}

\section{Introduction}

With the rapid development of China's rail transit industry, the demand for rail transit mobile equipment is currently increasing. Owing to heavy loads and high speeds, the wheels of trains and locomotives undergo wear, eventually resulting in wheel fatigue cracks, tread abrasions, and other damage. This significantly increases the maintenance workload of railway equipment enterprises. Wheels that reach their wear limit are typically subjected to high-temperature smelting; this approach, however, is energy intensive and also results in environmental pollution. Therefore, it is preferable to adopt the approach of "adding materials" in order to repair the wear of such wheels and restore their original appearance and performance for reuse. This is because, apart from curtailing pollution, this approach also reduces energy, time, and labor costs.

Laser cladding technology is not only widely employed in the fields of machinery, aviation, and aerospace but also employed in biomedical applications. An example of these purposes is the increase of material properties, such as the wear resistance [1], the corrosion resistance [2], the surface hardness [3], or the toughness [4] of the materials generated, among others. Many researchers have reported beneficial attempts in terms of applying this technology in the field of rail transit, particularly for studying the microstructure $[5,6]$, mechanical properties $[7,8]$, residual stress $[9,10]$, and wear and rolling contact fatigue [11-16] of laser-cladded wheels and rails. Wang et al. [17] applied laser cladding technology for repairing wheel and rail materials, focusing on evaluating the hardness and wear resistance of the specimens after laser cladding. The results of their study showed that, after laser cladding, the microhardness of the wheel and rail specimens increased significantly (by more than $40 \%$ ), and the wear resistance was four times greater than that before laser cladding. Yangxi et al. [18] studied the wear problem of a high-speed train wheelset repaired via laser cladding and determined the optimal process parameters for the orthogonal test. Their study showed that the hardness and wear resistance of the cladding specimens were improved considerably. Xinpeng et al. [19] cladded cobaltbased and iron-based alloys on wheel and rail materials, 
respectively, and studied the microstructure, hardness, and residual stress distributions of the cladded coatings. Rolling contact fatigue tests revealed that the wear performances of both the coated specimens were improved significantly, with the cobalt-based coatings exhibiting better performance.

Youzhong et al. [20] studied the feasibility of using laser cladding for the remanufacturing of EMU axles; for different cladding materials, they determined the appropriate remanufacturing process. Pressing tests on the remanufactured specimens showed that the remanufactured axles met the pressing requirements of EMU wheelsets. Furthermore, Lu et al. [14] reported significant improvements in the wear characteristics of R200 steel that was laser cladded with martensitic stainless steel powder, as compared with those of R260 steel.

Thus, significant research has been devoted to the field of rail transit, serving as a reference for further studies on the key components of locomotives and vehicles remanufactured via laser cladding technology. However, most of this research is limited to the laboratory stage; thus far, none of the previous studies have directly applied laser cladding technology for repairing locomotive and vehicle wheelsets. To address this gap in literature, in this study, laser cladding was used to remanufacture a damaged wheel. Wear damage and life evaluation models for the laser-cladded wheel were established for the purposes of quantitative evaluations.

\section{Wheel Remanufacturing via Laser Cladding}

The typical damage in locomotive and vehicle wheelsets includes abrasions and peeling of the wheel treads, fatigue cracks, and cracks in the wheel rims. The main method to repair the damaged wheel is non-falling wheel rotation, which means that the wheels are milled to restore their surface shape and operating state without breaking away from the car body. Non-falling wheel rotation is a "reducing material" processing method. However, this results in significant amounts of material waste. By contrast, repairing damaged components using laser cladding technology, i.e., the "adding materials" approach, considerably reduces material waste, while also affording reductions in energy consumption and environmental pollution.

In this study, laser cladding technology was used to remanufacture a wheel with scratched treads (Figure 1). The wheel is milled to restore the wheel morphology after cladding. Prior to the cladding process, acetone was used to clean the scratched portions of the wheel tread, and the cladding powder (Ni60) was dried. The height of the cladding layer is $3 \mathrm{~mm}$. The chemical composition of wheel material and cladding powder is shown in Table 1.

Laser cladding was performed using a fiber laser with a power of $2000 \mathrm{~W}$, current $(I)$ of $210 \mathrm{AA}$, pulse width $(\tau)$ of $3.5 \mathrm{~ms}$, frequency $(f)$ of $15 \mathrm{~Hz}$, cladding scanning speed $(\mathrm{v})$ of $180 \mathrm{~mm} / \mathrm{min}$, powder feeding rate of $6 \mathrm{~g} / \mathrm{s}$, laser spot diameter of $2 \mathrm{~mm}$, focal length of $300 \mathrm{~mm}$, and defocus amount (the distance between the laser focus and the upper surface of the work piece) of $+1.5 \mathrm{~mm}$. The remanufactured wheel is illustrated in Figure 2.

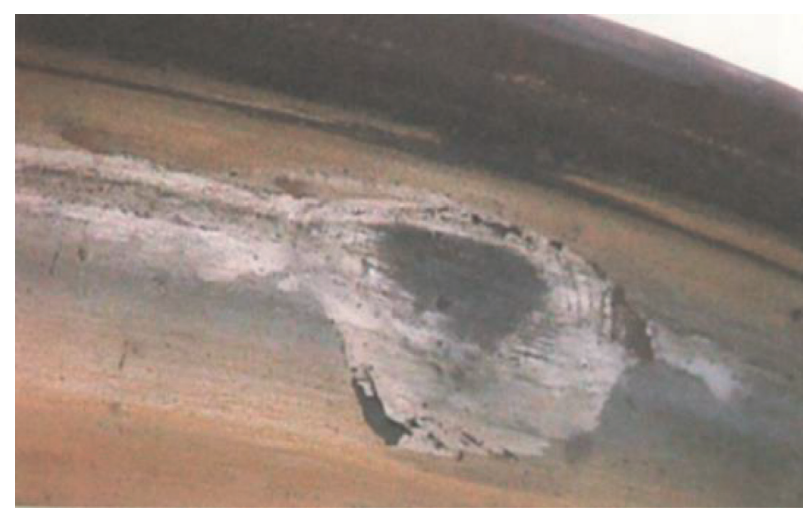

Figure 1: Wheel tread abrasion.

\section{Damage Assessment for Remanufactured Wheel}

The conventionally used wheel contact and abrasion damage models can be categorized as stable figure evaluation models and damage function evaluation models. However, the stability diagram evaluation model does not consider the wheel-rail contact with respect to creepage. As contact fatigue influences the wear, the precision of this model is relatively low. Therefore, this study employed the damage function evaluation model to evaluate wheel damage based on the wear number.

The damage function evaluation model considers the relationship between the wear and contact fatigue damage and also the influence of the creep force and creepage on the wheel rolling contact fatigue damage. The sum of the wear and fatigue damage represents the damage caused during a single wheel rotation. The wear number is calculated as follows [21]:

$$
T_{\gamma}=T_{x} \gamma_{x}+T_{y} \gamma_{y}
$$

where $T$ and $\gamma$ represent the creep force and creepage, respectively; these can be calculated using Simpack, a dynamic simulation software program for vehicles. The longitudinal and lateral expressions are denoted as $x$ and $y$, respectively.

The curve for the wheel's rolling contact fatigue damage function is presented in Figure 3.

Based on previous research results, the crack initiation value for the damage function is proportional to the shear yield strength of the material [17]. In this study, the shear yield strength of the cladding material for the remanufactured wheel was approximately $473 \mathrm{MPa}$, whereas the shear yield strength of the steel used in the wheel was $300 \mathrm{MPa}$. Based on the proportional relationship, the crack initiation value for the cladded wheel was determined to be $32 \mathrm{~N}$.

As the fatigue crack propagation rate directly affects the fatigue life of the component, the crack velocity parameter in the damage function can be modified according to the fatigue ratio of the matrix of the cladding component. Based on the ratio of the substrate life to the cladding life [22], the crack velocity of the remanufactured wheel was determined to be $5.6 \times 10^{-4} \mathrm{r} / \mathrm{N}$. 
TABle 1: Chemical composition of materials (mass fraction, \%).

\begin{tabular}{lccccccccccc}
\hline Material & $\mathrm{C}$ & $\mathrm{Si}$ & $\mathrm{B}$ & $\mathrm{Cr}$ & $\mathrm{P}$ & $\mathrm{V}$ & $\mathrm{Mn}$ & $\mathrm{Mo}$ & $\mathrm{S}$ & $\mathrm{Cu}$ & $\mathrm{Ni}$ \\
\hline Wheel & 0.56 & 0.4 & - & 0.3 & 0.02 & 0.06 & 0.8 & 0.08 & 0.02 & 0.3 & 0.3 \\
Ni60 & 0.8 & 3.1 & 4.0 & 15 & 0.09 & - & - & - & 0.8 & 1.1 & 75.11 \\
\hline
\end{tabular}

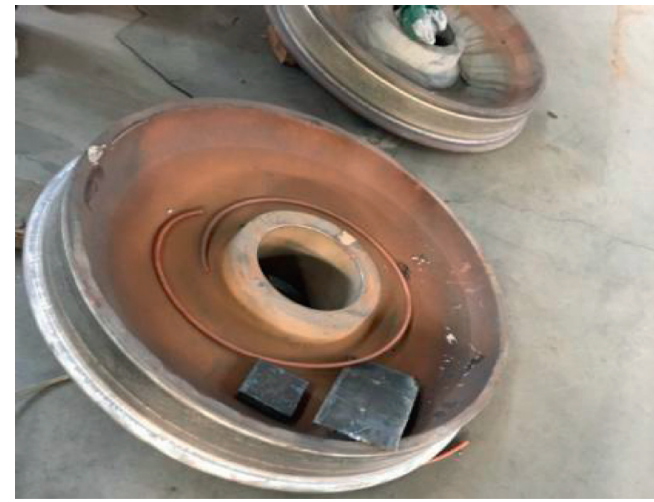

Figure 2: Wheel remanufactured using laser cladding.

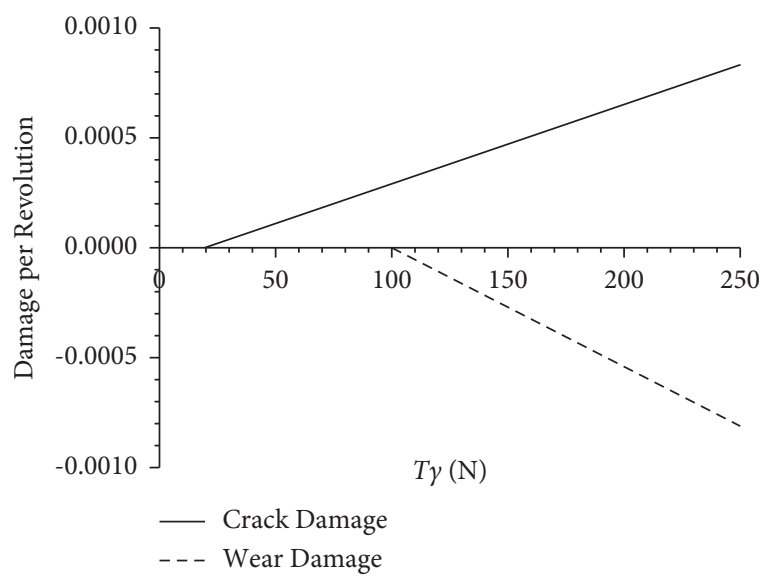

FIGURE 3: Damage function for rolling contact fatigue of the wheel [6].

Gongquan reported an approximate linear relationship between the wear coefficient in the damage function and the hardness of mechanical components [21]. The average hardness of the steel used in the wheel was approximately $280 \mathrm{HV}$, whereas the microhardness of the cladding layer of the remanufactured wheel in this study was approximately $800 \mathrm{HV}$. Based on the linear relationship between hardness and the wear number, the initial wear of the laser-cladded wheel was $285 \mathrm{~N}$, with a wear speed of $-1.9 \times 10^{-6} \mathrm{r} / \mathrm{N}$.

The damage function parameters for the matrix and the remanufactured wheel are listed in Table 2.

The number of abrasions in the remanufactured wheelset was calculated based on the revised damage function parameters for the remanufactured wheel. Subsequently, the compound damage per rolling cycle of the cladded wheel was determined. The complete life cycle for the total damage to the cladded wheel was calculated using Simpack, based on the creepage and the cross and longitudinal creep forces of the cladded wheel.
The wheel-rail module in Simpack, which exhibits high simulation accuracy and efficiency, has been verified through a large number of railway vehicle tests. It is the standard development tool for the dynamic simulations of railway vehicle systems utilized worldwide. In the simulation, $\mathrm{CRH} 2 \mathrm{EMU}$ was identified as the research object to establish the dynamic model, where the tread of the cladded wheel was the LMA tread, the rail was the CN60 rail, and the inner distance of the wheelset was $1353 \mathrm{~mm}$. During modeling, the $X, Y$, and $Z$ axes were defined as the forward direction of the EMU, the direction parallel to the right side of the track plane, and the direction perpendicular to the track plane below, respectively. The coordinate system is illustrated in Figure 4. The EMU body, frame (2), traction rod (2), and wheelset (4) were all assigned six degrees of freedom (longitudinal, transverse, vertical, side roll, nodding, and shaking head). The entire dynamic model of the EMU system featured 62 degrees of freedom.

Wheel wear and fatigue are mainly caused by frequently passing over curved sections. Therefore, this study focused on the dynamic performance of the research object when passing over a curved section. Measured track irregularity of Beijing-Tianjin line is used as the track excitation. The MU train speed was set as $200 \mathrm{~km} / \mathrm{h}$, and the wheel diameter was $860 \mathrm{~mm}$. A right curve was adopted, and the simulation time was $20 \mathrm{~s}$, as listed in Table 3.

The curves for the vertical and horizontal creep forces and the creepage, obtained via simulation, are presented in Figures 5-8 (inner wheel of wheelset 1).

Field observation shows that the longitudinal creep force of the wheel on one side of the inner rail is opposite to the direction of the vehicle when the vehicle curve passes, and the cracks on the surface of the wheel on the inner rail side and the surface of the outer rail are easier to propagate. Therefore, the wheel-rail damage is only calculated when the longitudinal creep force is opposite to the direction of the vehicle.

Based on (1), the average wear number of the cladded wheel was calculated as $364 \mathrm{~N}$. According to the damage function shown in Figure 3 and the parameters listed in Table 2, the damage $\left(D_{w}\right)$ caused by laser cladding remanufacturing of the wheel after passing through a given circuit can be calculated according to the following formula:

$$
\begin{aligned}
D_{w}= & {\left[(364-32) \times 5.6 \times 10^{-4}-(364-285) \times 1.9 \times 10^{-6}\right] } \\
& \times \frac{120}{3.14} \frac{4}{0.86} \\
= & 8.27 \times 10^{-3} .
\end{aligned}
$$


TABLe 2: Parameters of the wheel's rolling contact fatigue damage function.

\begin{tabular}{lcc}
\hline Damage function parameters & Values for matrix wheel & Values for remanufactured wheel \\
\hline Crack initiation value $(\mathrm{N})$ & 20 & 32 \\
Crack speed $(\mathrm{r} / \mathrm{N})$ & $2.6 \times 10^{-6}$ & $5.6 \times 10^{-4}$ \\
The starting value of wear $(\mathrm{N})$ & 100 & 285 \\
Wear rate $(\mathrm{r} / \mathrm{N})$ & $-5.4 \times 10^{-6}$ & $-1.9 \times 10^{-6}$ \\
\hline
\end{tabular}

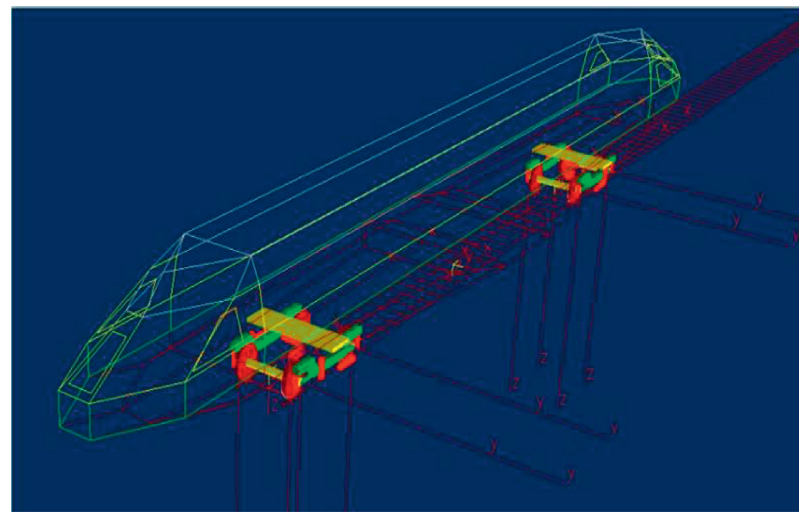

Figure 4: Dynamic model for simulation.

TABLE 3: Line conditions for the simulation [22].

\begin{tabular}{lc}
\hline Line conditions & Value \\
\hline Length of straight line $(\mathrm{m})$ & 200 \\
Length of easing curve $(\mathrm{m})$ & 320 \\
Length of circular curve $(\mathrm{m})$ & 120 \\
Curve radius $(\mathrm{m})$ & 2000 \\
Elevation of outer rail $(\mathrm{m})$ & 0.126 \\
\hline
\end{tabular}

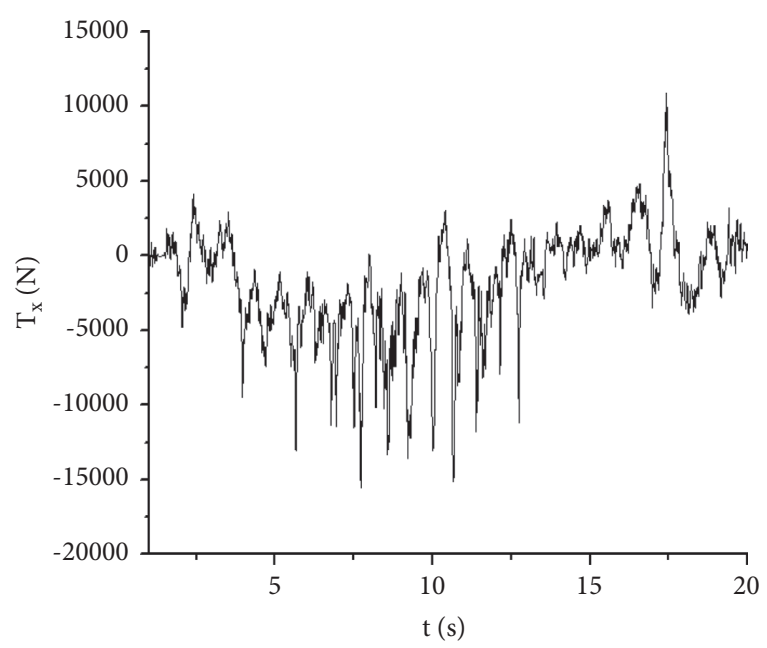

Figure 5: Longitudinal creep force of the wheel.

\section{Life Assessment for Remanufactured Wheel}

Chaboche and Lesne proposed the following relationship between damage and fatigue life under uniaxial fatigue [23]:

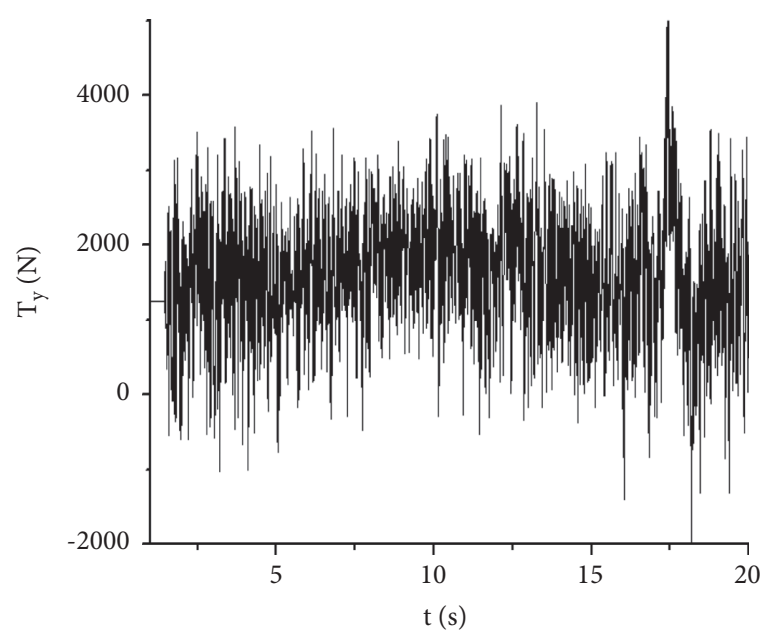

FIgURE 6: Lateral creep force of the wheel.

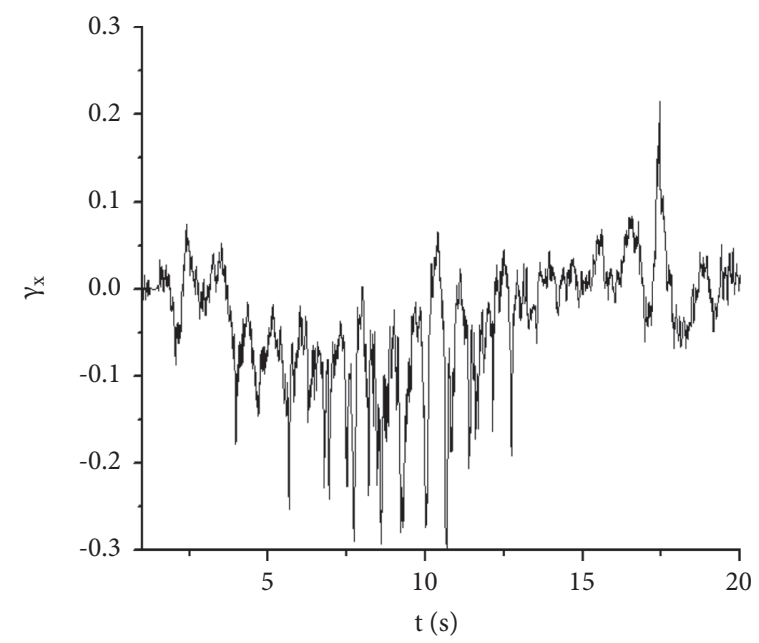

FIgURE 7: Longitudinal creepage of the wheel.

$$
d D=\left[1-(1-D)^{\beta+1}\right]^{\alpha}\left[\frac{\sigma_{a}}{M_{0}\left(1-b \sigma_{m}\right)(1-D)}\right]^{\beta} d N
$$

where $D$ is the damage variable; $N$ is the fatigue life; $\sigma_{a}$ is the stress amplitude; $\sigma_{m}$ is the average stress; $\beta, M_{0}$, and $b$ are parameters determined based on the material properties; and $\alpha$ is a parameter jointly determined by the damage and load, as expressed in the following equation $[24,25]$ : 


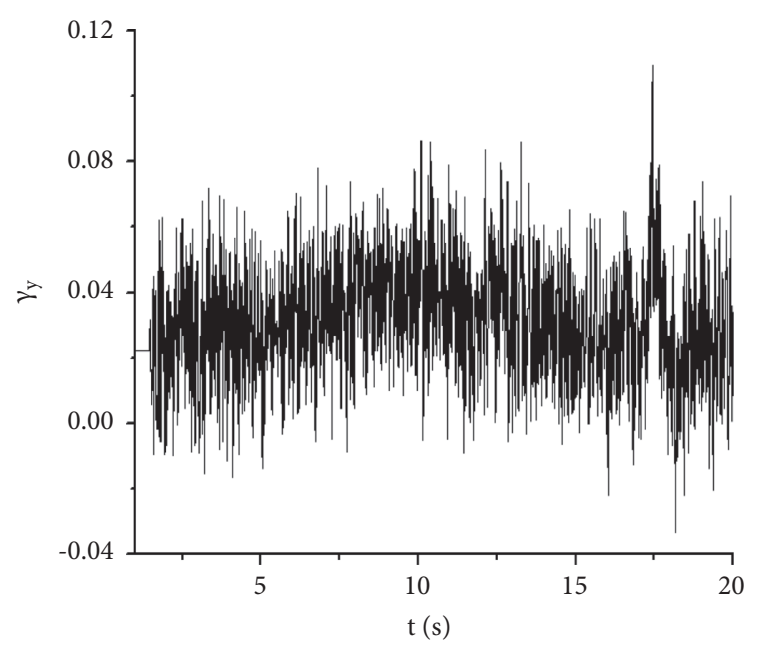

FIgURE 8: Lateral creepage of the wheel.

$$
\alpha=1-\frac{1}{H}\left\langle\frac{\sigma_{\max }-\sigma_{R}}{\sigma_{b}-\sigma_{\max }}\right\rangle^{a} .
$$

Here, if $x>0$, then $\langle x\rangle=x$; if $x \leq 0$, then $\langle x\rangle=0 . S_{\max }$ denotes the maximum stress, $\sigma_{R}$ denotes the fatigue limit of the material under the corresponding stress ratio $R, s_{b}$ denotes the strength limit of the material, and $H$ and $a$ are both experimental constants. Dattoma et al. [24, 25] suggested that for metals, $H=0.0801$ and $a=0.434$.

Previous studies have shown that both the residual tensile stress and the crack closure effect [26] can have a significant impact on the fatigue life of mechanical products. Considering the effects of the residual tensile stress and the crack closure effect when evaluating the damage to the laser cladding can help improve the accuracy of the damage model. Thus, (3) was modified as follows:

$$
\begin{aligned}
d D_{c \xi}= & {\left[1-\left(1-\xi D_{c}\right)^{\beta+1}\right]^{\alpha_{c}} } \\
& \cdot\left[\frac{\sigma_{a}}{M_{0}\left[1-b\left(\sigma_{m 0}+\sigma_{r \max }\right)\right]\left(1-\xi D_{c}\right)}\right]^{\beta} d N,
\end{aligned}
$$

where $d D_{c \xi}$ is the damage when considering the crack closure effect and $\xi$ is the effective factor of crack closure. The average stress was modified as [27]

$$
\sigma_{m}=\sigma_{m 0}+\sigma_{r \max }
$$

where $\sigma_{m 0}$ is the average stress when the residual tensile stress is neglected.

The effective crack closure factor corresponding to different stress ratios was calculated as follows [28]:

$$
\xi=0.75+0.3 R+0.15 R^{2}(-1 \leq R \leq 1) .
$$

If the initial damage to the cladded wheel is $D_{c t}$, then $0<D_{c t}<1$, and the life of the cladded wheel (i.e., until it fails) is $N_{f}$. In this case $D_{c \xi}=1$ and $D_{c \xi} \in\left(D_{c t}, 1\right)$. The fatigue life of the remanufactured wheel was obtained by integrating equation (5) over the interval, as shown in the following equation:

$$
\begin{aligned}
N_{f}= & \frac{1}{\xi} \frac{1}{1-\alpha_{c}} \frac{1}{1+\beta}\left[\frac{M_{0}\left[1-b\left(\sigma_{m 0}+\sigma_{r \max }\right)\right]}{\sigma_{a}}\right]^{\beta} \\
& \cdot\left\{\left[1-(1-\xi)^{\beta+1}\right]^{1-\alpha_{c}}-\left[1-\left(1-D_{c t}\right)^{1+\beta}\right]^{1-\alpha_{c}}\right\},
\end{aligned}
$$

where the values of the material constants are as follows [22]: $\beta=5.003, M_{0}=3985.423$, and $b=0.001$.

The stress ratio $(R)$ was assumed to be -1 ; furthermore, the wheel underwent no damage, the wheel-rail contact spot area was $100 \mathrm{~mm}^{2}$, and the length of the line with a small curve radius was $1 \%$ of the total length of the line. By considering the contact fatigue damage (calculated using (2)) as the initial damage to the remanufactured wheel and substituting it in (8), under the test conditions in this study, the operating mileage of the remanufactured wheel was approximately 1.64 million $\mathrm{km}$; this is slightly lower than the service life of wheels ( 2 million $\mathrm{km}$ ). This difference can be mainly attributed to two factors. First, the curve radius used in the simulation was harsh. The curve radii of actual lines are considerably larger than those considered in the simulation; hence, the remanufactured wheel is likely to undergo less damage on actual lines. As a result, the mileage would be closer to the design life of the wheel. Second, as certain parameters in the calculation model are significantly affected by the conditions of the laser cladding process, the lives of remanufactured wheels prepared under different process parameters would also be different.

\section{Conclusion}

In this study, laser cladding technology was used to repair a damaged wheel with tread abrasions. Combined with analyses of the vehicle dynamics, the existing damage evaluation model for railway wheels was modified. Using CRH2 EMU wheels as the research object, damage and life evaluation models for wheels remanufactured through the laser cladding process were established. The calculated results of the evaluation model met the requirements of wheel design, thus providing a new idea for the application and maintenance of railway wheels. This study is expected to promote the development of railway-related industries to a certain extent and also enable beneficial supplements in terms of improving the theoretical systems of remanufacturing engineering; this has evident scientific significance and engineering application value.

Owing to the diversity in models and wheel materials, the direct remanufacturing of damaged wheels using laser cladding technology is challenging, particularly given the strict requirements of the process. During the process of cladding and remanufacturing, protective measures should be implemented to ensure that the cladding layer and the heat-affected zone do not develop cracks or other defects that could affect the quality of remanufacturing, which, in turn, would affect the structure and mechanical properties of the remanufactured products. Laser cladding remanufacturing involves many aspects, such as metal technology, thermodynamics, elastoplastic mechanics, tribology, 
production technology, and processing equipment, all of which warrant further study.

\section{Data Availability}

Some or all data, models, and codes generated or used during the study are available in a repository or online in accordance with funder data retention policies. The data used to support the findings of this study can be offered by the authors upon request.

\section{Conflicts of Interest}

The authors declare that they have no conflicts of interest.

\section{Acknowledgments}

This research was funded by the Youth Foundation of National Natural Science Foundation of China (grant no. 51105205), the Excellent Scientific and Technological Innovation Team of Universities in Jiangsu Province (grant no. 2019042), the Science and Technology Foundation of Guizhou Province (grant no. 2019040), and the Natural Science Research Project of Jiangsu Universities (grant no. 21KJB580018). The authors are grateful for the support.

\section{References}

[1] V. Ocelík, U. de Oliveira, M. de Boer, and J. T. M. de Hosson, "Thick co-based coating on cast iron by side laser cladding: analysis of processing conditions and coating properties," Surface and Coatings Technology, vol. 201, no. 12, pp. 5875$5883,2007$.

[2] L. Chen and S.-L. Bai, "The anti-corrosion behavior under multi-factor impingement of Hastelloy C22 coating prepared by multilayer laser cladding," Applied Surface Science, vol. 437, pp. 1-12, 2018.

[3] R. Yang, Z. Liu, G. Yang, and R Weiyu, "Study of the Ti-20 wt. $\%$ Mo composite coating prepared by laser cladding," Procedia Engineering, vol. 36, pp. 355-359, 2012.

[4] Ó Barro, F. Arias-González, F. Lusquiños, and R Comesaña, "Improved commercially pure titanium obtained by laser directed energy deposition for dental prosthetic applications," Metals, vol. 11, no. 1, p. 70, 2021.

[5] V. Aladesanmi, O. Fatoba, and E. Akinlabi, "Laser cladded Ti + TiB2 on steel rail microstructural effect," Procedia Manufacturing, vol. 33, pp. 709-716, 2019.

[6] W. Xinlin, "Lei lei yu han. a review on microstructural features and mechanical properties of wheels/rails cladded by laser cladding," Micromachines, vol. 12, no. 2, pp. 152-163, 2021.

[7] L. Meng, X. Zeng, K. Hou, and Q. Hu, "Effect of laser cladding and laser-induction hybrid cladding coatings on the bending properties and fracture behavior of rails," Surface and Coatings Technology, vol. 374, pp. 1038-1050, 2019.

[8] T. Roy, R. Abrahams, A. Paradowska, and Q. Lai, "Evaluation of the mechanical properties of laser cladded hypereutectoid steel rails," Wear, vol. 432, pp. 824-829, 2019.
[9] T. Roy, A. Paradowska, R. Abrahams et al., "Residual stress in laser cladded heavy-haul rails investigated by neutron diffraction," Journal of Materials Processing Tech, vol. 278, pp. 278-291, 2020.

[10] A. Narayanan, M. Mostafavi, T. Pirling et al., "Residual stress in laser cladded rail," Tribology International, vol. 140, pp. 140-156, 2019.

[11] X. Tianxing, Z. Liang, D. Haohao, Y. Zhu, and W. Yang, "Investigation on the rolling contact fatigue behaviours of different laser cladding materials on the damaged rail," Journal of Tribology, vol. 143, no. 5, pp. 1-33, 2021.

[12] L. Meng, B. Zhu, C. Xian, X. Zeng, Q. Hu, and D. Wang, "Comparison on the wear properties and rolling contact fatigue damage behaviors of rails by laser cladding and laserinduction hybrid cladding," Wear, vol. 458-459, 2020.

[13] W. Gamon and K. Aniołek, "Examination of the sliding wear of bronze coatings on railway buffer heads," Wear, vol. 448-449, 2020.

[14] P. Lu, S. R. Lewis, S. Fretwell-Smith, D. L. Engelberg, D. I. Fletcher, and R. Lewis, "Laser cladding of rail; the effects of depositing material on lower rail grades," Wear, vol. 438-439, 2019.

[15] Y. Zhu, Y. Yang, X. Mu, W. Wang, Z. Yao, and H. Yang, "Study on wear and RCF performance of repaired damage railway wheels: a," Wear, vol. 430-431, pp. 126-136, 2019.

[16] S. Jung-Won, K. Jae-Chul, K. Seok-Jin, and J. Hyun-Kyu, "Effects of laser cladding for repairing and improving wear of rails," International Journal of Precision Engineering and Manufacturing, vol. 20, no. 7, pp. 1207-1217, 2019.

[17] W. J. Wang, J. Hu, J. Guo, Q. Y. Liu, and M. H. Zhu, "Effect of laser cladding on wear and damage behaviors of heavy-haul wheel/rail materials," Wear, vol. 311, pp. 1-2, 2014.

[18] D. Yangxi, Y. Yingqun, S. Xiaofeng, and D. Jie, "Research on laser cladding reparation of ER8 tread wear of high-speed train wheel," Hot Working Technology, vol. 46, no. 18, pp. 164-167, 2017.

[19] M. Xinpeng, W. Wenjian, Z. Yi, Q. Y. Liu, J. Guo, and H. H. Ding, "Effects of two laser cladding coatings on wear and damage properties of wheel/rail materials," Tribology, vol. 40, no. 2, pp. 225-233, 2020.

[20] H. Youzhong, Q. Xiansheng, D. Hongjian et al., "Material selection and mechanical property evaluation for additively remanufactured EMU axles," Surface Technology, vol. 49, no. 12, pp. 162-168, 2020.

[21] T. Gongquan, Preliminary Study on the of Wheel Tread Shelling of KKD Passenger Car, Southwest Jiaotong University, Cheng Du, China, 2013.

[22] H. Liang, Fatigue Life Evaluation On The Laser Cladding Remanufactured Product Fatigue Life, Nanjing University of Aeronautics and Astronautics, NanJing, China, 2017.

[23] J. L. Chaboche and P. M. Lesne, "A non-linear continuous fatigue damage model," Fatigue and Fracture of Engineering Materials and Structures, vol. 11, no. 1, pp. 1-17, 1988.

[24] V. Dattoma, S. Giancane, R. Nobile, and F. Panella, "Fatigue life prediction under variable loading based on a new nonlinear continuum damage mechanics model," International Journal of Fatigue, vol. 28, no. 2, pp. 89-95, 2006.

[25] S. Giancane, R. Nobile, F. W. Panella, and V. Dattoma, "Fatigue life prediction of notched components based on a 
new nonlinear continuum damage mechanics model," Procedia Engineering, vol. 2, no. 1, pp. 1317-1325, 2010.

[26] T.-L. Teng and P.-H. Chang, "Effect of residual stresses on fatigue crack initiation life for butt-welded joints," Journal of Materials Processing Technology, vol. 145, no. 3, pp. 325-335, 2004.

[27] W. A. N. G. Guangzhong, Fatigue of Material, National Defence Industry Press, Beijing, China, 1999.

[28] L. I. Xinlei, R. E. N. Jilin, and R. E. N. Shangkun, "Residual life assessment of ferromagnetic components," Acta Aeronautica et Astronautica Sinica, vol. 31, no. 10, pp. 2109-2114, 2010.

[29] L. Xinlei, R. Jilin, R. Shangkun, C. Xi, and F. Renzhen, "Residual life assessment of ferromagnetic components," Acta Aeronautica et Astronautica Sinica, vol. 31, no. 10, pp. 2109-2114, 2010. 